\title{
Fitness Traits of Deoxynivalenol and Nivalenol-Producing Fusarium graminearum Species Complex Strains from Wheat
}

Camila Primieri Nicolli, Departamento de Fitossanidade, Universidade Federal do Rio Grande do Sul, 91540-000, Porto Alegre, RS, Brazil; and Franklin Jackson Machado, Piérri Spolti, and Emerson M. Del Ponte, ${ }^{\dagger}$ Departamento de Fitopatologia, Universidade Federal de Viçosa, 36570-000, Viçosa, MG, Brazil

\begin{abstract}
Fusarium graminearum of the 15-acetyl-deoxynivalenol (15-ADON) chemotype is the main cause of Fusarium head blight (FHB) of wheat in southern Brazil. However, 3-ADON and nivalenol (NIV) chemotypes have been found in other members of the species complex causing FHB in wheat. To improve our understanding of the pathogen biology and ecology, we assessed a range of fitness-related traits in a sample of 30 strains representatives of $15-\mathrm{ADON}$ ( $F$. graminearum), 3-ADON ( $F$. cortaderiae and $F$. austroamericanum), and NIV ( $F$. meridionale and $F$. cortaderiae). These included perithecia formation on three cereal-based substrates, mycelial growth at two suboptimal temperatures, sporulation and germination, pathogenicity toward a susceptible and a moderately resistant cultivar, and sensitivity to tebuconazole. The most important trait favoring $F$. graminearum was a two times higher sexual fertility ( $>40 \%$ perithecial production index $[\mathrm{PPI}])$ than

the other species $(<30 \%$ PPI); PPI varied among substrates (maize $>$ rice $>$ wheat). In addition, sensitivity to tebuconazole appeared lower in $F$. graminearum, which had the only strain with effective fungicide concentration to reduce $50 \%$ of mycelial growth $>1 \mathrm{ppm}$. In the pathogenicity assays, the deoxynivalenol producers were generally more aggressive (1.5 to $2 \times$ higher final severity) toward the two cultivars, with $3-A D O N$ or $15-A D O N$ leading to higher area under the severity curve than the NIV strains in the susceptible and moderately resistant cultivars, respectively. There was significant variation among strains of the same species with regards asexual fertility (mycelial growth, macroconidia production, and germination), which suggested a strain- rather than a species-specific difference. These results contribute new knowledge to improve our understanding of the pathogenrelated traits that may explain the dominance of certain members of the species complex in specific wheat agroecosystems.
\end{abstract}

Fusarium head blight (FHB) is a major disease of wheat and smallgrain crops due to the reduction in yield and contamination of grain with dangerous mycotoxins (McMullen et al. 2012). Deoxynivalenol (DON) is the most significant mycotoxin given its widespread occurrence at levels of concern to human and animal health (Tanaka et al. 1988). However, nivalenol (NIV), another type-B trichothecene, has been found in commercial wheat samples from Brazil (Del Ponte et al. 2015) and also in inoculations of wheat under controlled conditions (Mendes et al. 2018; Nicolli et al. 2015). A molecular survey conducted during the last decade showed that Fusarium graminearum (O'Donnell et al. 2004), formerly lineage 7 (O'Donnell et al. 2000), is the main ( $>85 \%$ frequency) $F$. graminearum species complex (FGSC) member causing FHB of wheat in Brazil (Del Ponte et al. 2015 ). The $F$. graminearum strains found in Brazilian wheat and barley analyzed thus far are exclusively of the 15-acetyl(A)DON genotype, a mainly DON producer (Astolfi et al. 2012; Castañares et al. 2016; Del Ponte et al. 2015). F. meridionale, a NIV-producing species, is the second most dominant FHB pathogen ( $>15 \%$ overall) and an important regional contributor of FHB in the major wheat-producing region of Brazil, Paraná State, where its frequency increases to approximately $30 \%$ in wheat spikes and grain (Del Ponte et al. 2015). This species is the main cause ( $>96 \%$ frequency) of Gibberella ear rot and stalk rot as well the most frequent species surviving on maize stubbles, a large reservoir of inoculum for FHB epidemics (Del Ponte et al. 2015; Kuhnem et al. 2015).

${ }^{\dagger}$ Corresponding author: E. M. Del Ponte; E-mail: delponte@ufv.br

Funding: The Programa de Pós-graduação em Fitotecnia (UFRGS) and CNPq-Conselho Nacional de desenvolvimento Científico e Tecnológico provided a graduate scholarship CNPq to C. P. Nicolli.

*The $\boldsymbol{e}$-Xtra logo stands for "electronic extra" and indicates that one supplementary figure is published online.

Accepted for publication 22 January 2018.

(c) 2018 The American Phytopathological Society
Other FGSC members that occur at smaller frequency in wheat include $F$. cortaderiae and $F$. austroamericanum that possess either 3 ADON or NIV trichothecene genotype (Del Ponte et al. 2015). NIV, as well as 3-ADON strains within FGSC members, are actually much less common in wheat grown in the Americas, especially in Brazil (Del Ponte et al. 2015); however, there are concerns about their ability to produce different or greater amounts of trichothecenes (Mendes et al. 2018; Umpiérrez-Failache et al. 2013) and potential shifts in climate that may favor build-up of inoculum of the currently minor species (Juroszek and von Tiedemann 2013; Vaughan et al. 2016). In the state of Louisiana in the United States, NIV-type populations of $F$. graminearum, which were found at high frequency (79\%) among isolates from small-grain-growing regions, accumulated four times less trichothecene toxin than DON types on inoculated wheat (Gale et al. 2011). The 3-ADON strains of $F$. graminearum, which appeared to emerge and spread into some regions of North America, were able to produce higher quantities of total trichothecenes and exhibit higher fecundity and growth rates than 15-ADON strains (Ward et al. 2008). More recently, the aggressiveness of $F$. graminearum strains of the 15-ADON or 3-ADON genotypes from New York toward a susceptible wheat cultivar did not differ, thus suggesting no apparent advantage of 3-ADON compared with the 15-ADON genotype, although the former produced significantly greater amounts of trichothecenes (Spolti et al. 2014a).

In the south of Brazil, in addition to the dominant $F$. graminearum of the 15-ADON chemotype population, 3-ADON strains were found only in $F$. cortaderiae and $F$. austroamericanum isolates, whereas the NIV genotype was found in $F$. cortaderiae, $F$. meridionale, and $F$. asiaticum (Del Ponte et al. 2015). The 3-ADON strains from wheat were found at higher elevation regions with cooler winter and spring seasons, which suggested that climate, in addition to cereal hosts, could also shape species composition (Del Ponte et al. 2015). A recent study comparing 15-ADON and NIV strains of $F$. graminearum from China showed that the former grew faster at both 20 and $25^{\circ} \mathrm{C}$, produced higher amounts of perithecia, and were more aggressive toward a wheat cultivar (Liu et al. 2017). These findings of enhanced aggressiveness of the 15-ADON agree with studies in Brazil, although the NIV strains were of a different species (F. meridionale) (Spolti and Del Ponte 2013; Spolti et al. 2012a). The toxigenic potential of $F$. graminearum also appeared to be higher than $F$. meridionale because much greater 
amount of DON was produced compared with NIV produced by the latter (Nicolli et al. 2015).

Empirical knowledge of some components of the life cycle of FGSC members other than $F$. graminearum and $F$. meridionale in Brazil, such as the saprophytic ability and whether this is influenced by the cereal-based substrate and temperature, which may provide competitive advantages for a species to build up inoculum for further spread, are not available. In this study, a sample of 30 strains representative of three trichothecene genotypes among four FGSC members associated with FHB of wheat in southern Brazil was selected to investigate the fitness-related traits related to both the saprophytic and pathogenic phase.

\section{Materials and Methods}

Isolates and experiments. The 30 isolates selected for this study originated from surveys of symptomatic wheat spikes in commercial fields during four seasons (2007-08 to 2011-12) in southern Brazil. These were accurately identified to species and trichothecenes genotypes using polymerase chain reaction (PCR)-based and multilocusgenotyping assays (Astolfi et al. 2012; Del Ponte et al. 2015). The strains were deposited and are available upon request at a mycological collection (Coleção Micológica de Lavras). Detailed information for these strains is shown in Table 1, which indicates in which experiments they were used. In total, five different experiments were conducted to assess saprophytic (sexual and asexual reproduction) and pathogenic (severity toward two cultivars) characteristics, and sensitivity to a triazole fungicide (tebuconazole).

Perithecial production. Perithecial production, as indicative of sexual fertility, was evaluated using kernel-based substrates composed of a distinct cereal host: wheat, rice, or maize. The method was adapted from Chen and Zhou (2009). Briefly, $20 \mathrm{~g}$ of grain was soaked in $10 \mathrm{ml}$ of distilled water and autoclaved for $20 \mathrm{~min}$ at $127^{\circ} \mathrm{C}$ daily during two consecutive days. Afterward, kernels were inoculated with three discs ( $6 \mathrm{~mm}$ in diameter) of mycelia and kept in the dark for 21 days at $25^{\circ} \mathrm{C}$. Then, the colonized grains were transferred to a bench in a greenhouse with controlled temperature $(25 \pm$ $3^{\circ} \mathrm{C}$ ) where they remained for 7 days for drying. After drying, they were placed in a plastic box ( 11 by 11 by $3.5 \mathrm{~cm}$ ) containing a sterile sand layer $(2 \mathrm{~cm})$ and three sheets of filter paper on top of the sand. The filter paper was moistened daily with sterile distilled water. After 21 days, 50 grains were randomly selected from each substrateisolate combination and individually scored visually using a diagrammatic key developed for this study, which contains four scores representing a percent range for the grain surface covered with perithecia (Supplementary Fig. S1). The frequency of the scores for each species-genotype combination (five groups) was normalized to a perithecial production index (PPI, \%) given by: PPI $=\left[\left(n_{1} \times 1\right)+\right.$ $\left.\left.\left(n_{2} \times 2\right)+\left(n_{3} \times 3\right)+\left(n_{4} \times 4\right)\right] \times 100\right) /\left(n_{\text {total }} \times 4\right)$, where $n_{x}=$ number of grains in the respective $x$ category $(x=1$ to 4 score $)$ and $n_{\text {total }}=$ total number of grains ( 25 in this study).

Mycelial growth. Isolates grown on potato dextrose agar (PDA) media (20 ml per dish) for 7 days at $25^{\circ} \mathrm{C}$ in continuous darkness provided mycelial discs (6 $\mathrm{mm}$ in diameter) which were individually placed in the center of plastic Petri dishes $(90 \mathrm{~mm}$ in diameter). The cultures were incubated in growth chambers at two regimes of suboptimal constant temperature $\left(15\right.$ or $\left.30^{\circ} \mathrm{C}\right)$ under continuous darkness for 5 days, when the diameter of the colony was measured from two perpendicular directions. The mycelial growth rate (MGR; millimeters per day) was calculated after subtracting the mycelium plug size (Spolti et al. 2012b). Three replicates (plates) were used per treatment.

Sporulation and germination. The asexual fecundity of the strains was evaluated based on the macroconidia production in culture medium. Isolates were grown on synthetic nutrient agar media

Table 1. Information for a collection of 30 strains belonging to four phylogenetic species of the Fusarium graminearum species complex isolated from symptomatic wheat heads from fields in Rio Grande do Sul State, Brazil, which were used in five different experiments in this study

\begin{tabular}{|c|c|c|c|c|c|}
\hline CML code ${ }^{a}$ & Location & Year of isolation & Species $^{b}$ & Genotype $^{b}$ & Experiment ${ }^{\mathrm{c}}$ \\
\hline 3065 & Panambi & 2009 & F. graminearum & $15-A D O N$ & $2,3,4$ \\
\hline 3066 & Ijuí & 2009 & F. graminearum & $15-\mathrm{ADON}$ & 1,4 \\
\hline 3067 & Carazinho & 2010 & F. graminearum & 15-ADON & $1,2,3,4$ \\
\hline 3071 & Tapejara & 2010 & F. graminearum & 15-ADON & $1,2,3,4,5$ \\
\hline 3069 & Coxilha & 2010 & F. graminearum & $15-A D O N$ & $1,2,4,5$ \\
\hline 3070 & Santa Bárbara do Sul & 2011 & F. graminearum & 15-ADON & $1,2,4$ \\
\hline 3830 & Não-Me-Toque & 2011 & F. graminearum & 15-ADON & $1,2,3$ \\
\hline 3833 & Não-Me-Toque & 2011 & F. graminearum & $15-\mathrm{ADON}$ & 1 \\
\hline 3064 & Cruz Alta & 2007 & F. graminearum & 15-ADON & $1,4,5$ \\
\hline 3068 & Ernestina & 2007 & F. graminearum & $15-A D O N$ & $1,2,3,4,5$ \\
\hline 3382 & Caseiros & 2010 & F. austroamericanum & $3-A D O N$ & $1,2,3,5$ \\
\hline 3384 & Barreto & 2010 & F. austroamericanum & 3-ADON & $1,2,3,4,5$ \\
\hline 3379 & Carazinho & 2010 & F. cortaderiae & 3-ADON & $1,2,3,4,5$ \\
\hline 3845 & Lagoa Vermelha & 2010 & F. cortaderiae & 3-ADON & $1,2,3,4$ \\
\hline 3841 & Lagoa Vermelha & 2010 & F. cortaderiae & 3-ADON & $1,2,3,4,5$ \\
\hline 3831 & Panambi & 2009 & F. cortaderiae & NIV & $1,2,3,4,5$ \\
\hline 3836 & Coronel Barros & 2009 & F. cortaderiae & NIV & $1,2,4$ \\
\hline 3837 & Coronel Barros & 2009 & F. cortaderiae & NIV & $1,2,3,4,5$ \\
\hline 3840 & Mato Castelhano & 2010 & F. cortaderiae & NIV & $1,2,4$ \\
\hline 3834 & Barreto & 2010 & F. cortaderiae & NIV & $1,2,4$ \\
\hline 3378 & Vacaria & 2010 & F. cortaderiae & NIV & $1,2,3,4,5$ \\
\hline 3835 & Ernestina & 2007 & F. cortaderiae & NIV & $1,2,3,4$ \\
\hline 3375 & Santa Bárbara do Sul & 2009 & F. meridionale & NIV & $1,2,4$ \\
\hline 3843 & Ernestina & 2009 & F. meridionale & NIV & $1,2,3,4$ \\
\hline 3344 & Coxilha & 2009 & F. meridionale & NIV & $1,2,3,4,5$ \\
\hline 3381 & Caseiros & 2010 & F. meridionale & NIV & $1,2,3,4,5$ \\
\hline 3839 & Marau & 2011 & F. meridionale & NIV & $1,2,3,4,5$ \\
\hline 3377 & Sertão & 2011 & F. meridionale & NIV & $1,2,3,4$ \\
\hline 3838 & Nonoai & 2007 & F. meridionale & NIV & $1,2,3,4$ \\
\hline 3374 & Nonoai & 2007 & F. meridionale & NIV & $1,2,4$ \\
\hline
\end{tabular}

${ }^{a}$ Culture collection code: CML = Coleção Micológica de Lavras, Universidade Federal de Lavras, Lavras, Minas Gerais, Brazil.

${ }^{\mathrm{b}}$ Species and trichothecene genotype identified using the multilocus genotype method as in previous study (Del Ponte et al. 2015): 15-ADON = 15-acetyl-deoxynivalenol, 3 -ADON = 3-acetyl-deoxynivalenol; and NIV = nivalenol.

${ }^{c}$ Experiments: 1 = perithecial production, $2=$ mycelial growth, $3=$ sporulation and germination, $4=$ pathogenicity, and $5=$ sensitivity to tebuconazole. 
for 7 days under a cycle of $12 \mathrm{~h}$ of light and $12 \mathrm{~h}$ of darkness at $25^{\circ} \mathrm{C}$ (Leslie and Summerell 2006). After this period, three discs $(6 \mathrm{~mm}$ in diameter) were removed from the edges of the developing colonies and immersed in $5 \mathrm{ml}$ of sterile water containing $0.1 \mathrm{ml}$ of Tween $0.001 \%$ in a test tube and shaken for $20 \mathrm{~s}$. The spore numbers were counted and the sporulation expressed as number of spores per milliliter. Spore germination was observed for a subsample of 20 spores (three replicated slides) after $6 \mathrm{~h}$ of exposure to water and results were expressed as percentage of germinating spores.

Pathogenicity. The pathogenicity of the strains was evaluated using a susceptible (BRS 194) and a moderately resistant (BRS Guamirim) cultivar. Seed were sown in plastic pots (3 liters) containing carbonized rice husk substrate (Tropstrato HT vegetables) fertilized with macronutrients (NPK 4-14-8). After seedling emergence, plants were thinned to obtain 10 plants/pot. Inoculations were performed during the milk stage of grain development of the main tillers of the plants using the centralspikelet method (Engle et al. 2003). The midposition spikelet (sixth from top to bottom) was marked with a pen and $20 \mu \mathrm{l}$ of a spore suspension $\left(10^{5}\right.$ conidia $\left./ \mathrm{ml}\right)$ was gently applied inside the floret with the aid of a micropipette (Spolti et al. 2012b). After inoculation, the plants were kept at constant temperature $\left(25^{\circ} \mathrm{C}\right)$ and relative humidity (approximately $70 \%$ ) to induce infection. The proportion of diseased spikelets in the wheat head was evaluated every 3 to 5 days during 3 weeks after inoculation. The experiment was repeated once in time and the data combined for analysis. The area under the diseased progress curve (AUDPC) was calculated and used to evaluate the effect of the trichothecene genotypes.

Sensitivity to tebuconazole. Tebuconazole sensitivity was quantified by measuring mycelial growth on PDA media amended with increasing fungicide concentrations (Becher et al. 2010; Spolti et al. 2014b). A stock solution (100 $\mu \mathrm{g}$ active ingredient [a.i.]/ml) was adjusted by dilution of the commercial formulation (Folicur 200 EC, $20 \%$ a.i.; BAYER S.A.) in distilled water. The stock solution was added to cooled PDA to obtain tested concentrations of $0.0,0.5$, $1.0,2.0,4.0$, and $8.0 \mu \mathrm{g}$ a.i./ml. One mycelia agar disc $(6 \mathrm{~mm}$ in diameter) obtained from the edge of a 7-day-old culture was placed at the central position of a Petri dish $(90 \mathrm{~mm})$ containing $15 \mathrm{ml}$ of PDA amended with the fungicide at each concentration. After 4 days of incubation at $25^{\circ} \mathrm{C}$ in darkness, radial growth was measured in two perpendicular directions and the disc diameter was subtracted. For each repeat of the experiment, two replicates were used. The effective fungicide concentration to reduce $50 \%$ of mycelial growth $\left(\mathrm{EC}_{50}\right)$ was determined using a linear regression model, as described elsewhere (Becher et al. 2010; Spolti et al. 2014b).

Data processing and analyses. All data processing and analyses, as well as graphical work, were performed running $\mathrm{R}$ version 3.4.3 (R Core Team 2017). Texts and scripts were prepared as R Markdown documents. A collection of these latter files were rendered as a website, using the render_site function of the $\mathrm{R}$ package rmarkdown (Allaire et al. 2017), where all analyses are documented, reproducible, and openly available at https://github.com/emdelponte/paperFGSC-fitness. The data in text format are deposited at the Open Science Framework data repository and available at https://osf.io/c2mbr/.

For the data from the experiments to evaluate saprophytic growth (perithecia formation, mycelial growth, and sporulation or germination) and pathogenicity, a multilevel linear mixed model was used to test the effects of the interaction, whenever present (e.g., temperaturegenotype, temperature-species, or species-genotype combinations), or the single effect of a factor on the response variable at 0.05 significance level. In the model, replication for the isolates and isolates within each species-genotype or trichothecene genotype, depending on the experiment, were treated as random effects. The lsmeans and respective confidence intervals were obtained using emmeans package (Lenth 2017) using kenward rogers $d f$ approximation. A Tukey method was used for comparing the means $(\alpha=0.05)$ whenever the effect was deemed significant. The mycelial growth and pathogenicity assays were repeated once in time and the others performed only once. Finally, the experiment to obtain $\mathrm{EC}_{50}$ values was repeated once in time and the data were combined for analysis. The means and confidence intervals were calculated.

\section{Results}

Saprophytic fitness. The proportion of grains with scores $>1$ (or $>10 \%$ kernel area covered with perithecia) was apparently higher for maize and rice kernel substrates compared with wheat and for the 15-ADON isolates compared with NIV and 3-ADON (Fig. 1A). All interactions tested in the model (species, genotypes, or species-genotype combined versus substrates) significantly affected PPI $(P<0.001)$, which was highest $(>50 \%)$ for 15 -ADON $F$. graminearum strains inoculated on rice and maize and lowest for inoculations on wheat kernels (Fig. 1B). There was a general trend of decreasing PPI in the wheat kernel substrate compared with the rice and maize substrates, as well as in the 3-ADON strains compared with the 15ADON strains. For the two NIV-producing species, PPI was higher in $F$. meridionale strains than in $F$. cortaderiae strains inoculated in rice and maize but not in wheat. There was no difference $(P>0.05)$ in PPI between the two 3-ADON species, regardless of the substrate.

As expected, mean values of MGR were $84 \%$ higher at $30^{\circ} \mathrm{C}$ $(0.7 \mathrm{~mm} /$ day $)$ than at $15^{\circ} \mathrm{C}(1.2 \mathrm{~mm} /$ day $)$ regardless of the trichothecene genotype. Within each of the temperatures, there were no differences in MGR means among the trichothecene genotypes $(P>0.20)$ as well as between species within trichothecene genotypes (Fig. 2A). The variation in MGR was apparently higher within 15-ADON strains compared with the others, especially for the high temperature.

All strains yielded macroconidia and there were differences in conidia production among the genotypes $(P=0.057)$, which were more

$$
\text { A Score } \square_{0} \square_{1} \square_{2} \square_{3}
$$
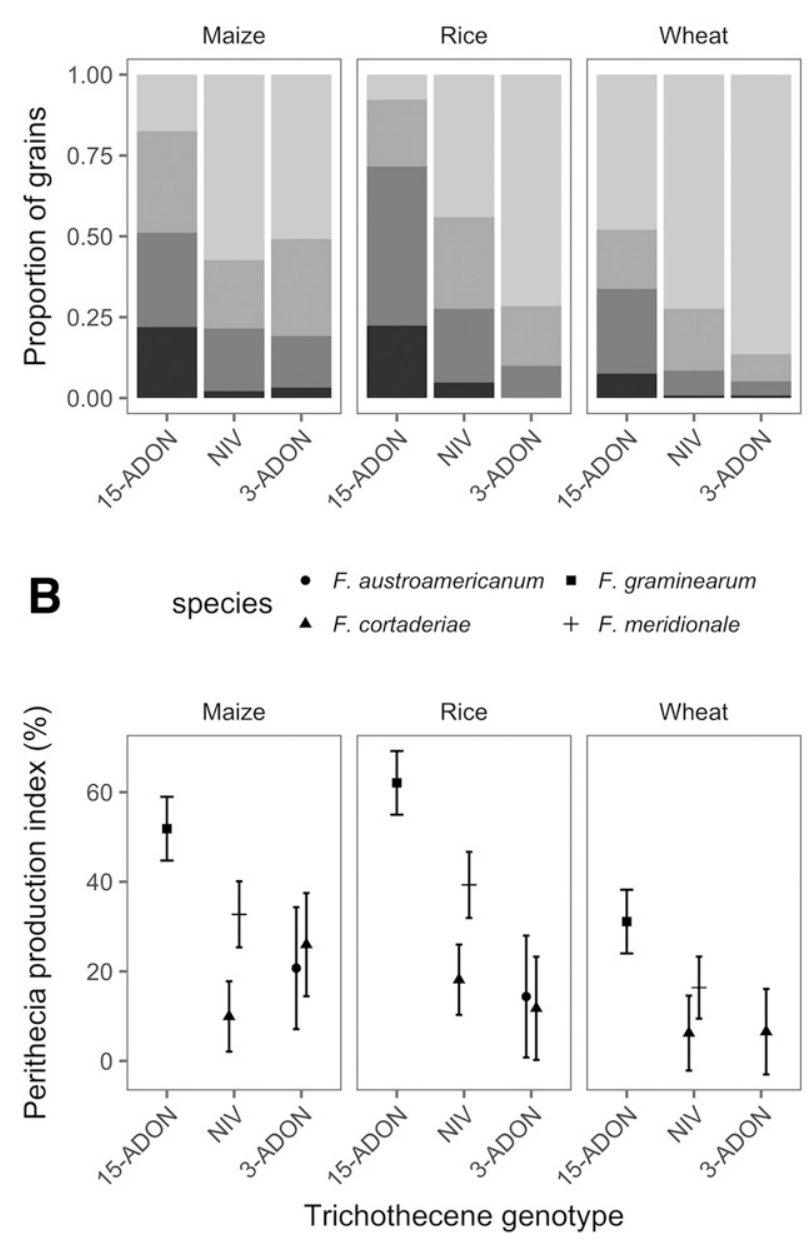

Fig. 1. A, Relative frequency of perithecial production scores based on a visual ordinal (0-to-3) scale for the proportion of grains in each score for the three different cerealbased substrates (wheat, rice, or maize kernels) and $\mathbf{B}$, the least square means and $95 \%$ confidence interval for the perithecial production index, which is a normalization of the frequency of the scores. Abbreviations: 15-ADON = 15-acetyl-deoxynivalenol, $\mathrm{NIV}=$ nivalenol, and 3-ADON = 3-acetyl-deoxynivalenol. 
evident when species-genotypes were compared $(P<0.001)$. The most prolific species was $F$. meridionale $\left(2.18 \times 10^{3}\right.$ spores $\left./ \mathrm{ml}\right)$, which differed significantly from the other species $\left(0.58\right.$ to $0.9 \times 10^{3}$ spores $\left./ \mathrm{ml}\right)$ but not from $F$. graminearum $\left(1.50 \times 10^{3}\right.$ spores $\left./ \mathrm{ml}\right)$ (Fig. $\left.2 \mathrm{~B}\right)$.

The germination rate ranged from 0 to $100 \%$ across the strains. The greatest variability ( $80 \%$ range) was found for the $F$. graminearum strains, followed by $F$. austroamericanum, for which the two strains differed by $>70 \%$. Therefore, the effect of genotype was not significant $(P=0.17)$ but, when species-genotype was compared, the mean germination rate of $F$. meridionale $(10.5 \%)$ differed significantly from $F$. graminearum $(50 \%)$ and $F$. cortaderiae NIV (52.8\%).

Pathogenicity. FHB severity (proportion of symptomatic spikelets) increased over time and ranged from 10 to $40 \%$ in the two cultivars. Regardless of the species, disease progress appeared slower during the first 10 days after inoculation $(<10 \%)$ for the moderately resistant cultivar (BRS Guamirim) compared with the susceptible cultivar (BRS 194), for which the progress peaked and stabilized at 15 to $35 \%$ after 10 days (Fig. 3). No formal test was used to compare these two cultivars because they were evaluated in different experiments.

Results of the mixed model to test the effect of genotype in the mean area under the severity curve showed that 15 -ADON F. graminearum (430.35 \pm 39.5 standard error [SE]) was significantly higher $(P<0.05)$ than the 3-ADON-producing $(314.30 \pm 53.65 \mathrm{SE})$ and NIV-producing $(324.81 \pm 28.01 \mathrm{SE})$ species when inoculated in the moderately resistant BRS Guamirim. On the other hand, the area under the severity curve did not differ significantly $(P=0.20)$ among the three trichothecene genotypes inoculated on BRS 194, although
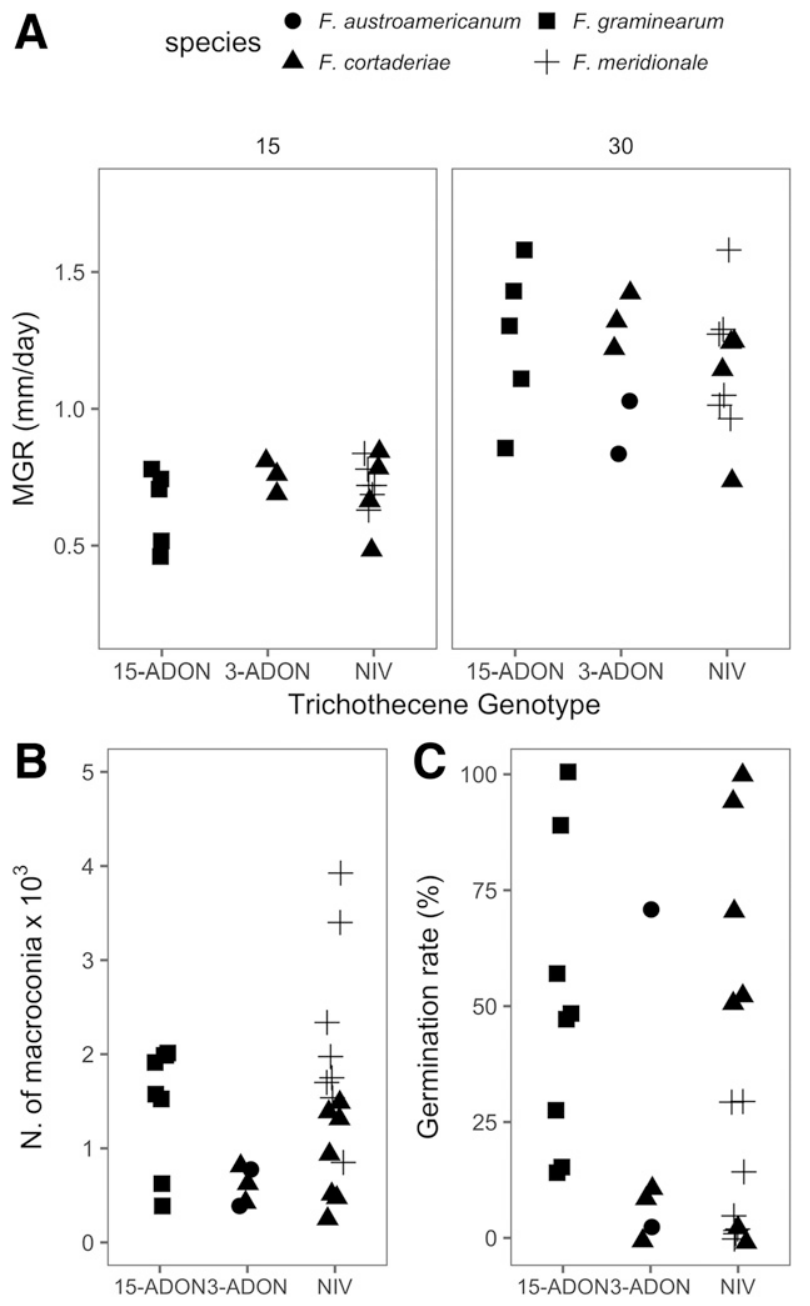

Fig. 2. Mycelial growth rate (MGR) and spore production by strains of four Fusarium graminearum species complex members possessing a nivalenol (NIV) or an acetylate form of deoxynivalenol (DON) genotype (3-ADON or 15-ADON) assessed based on A, mycelial growth at 15 or $30^{\circ} \mathrm{C}$; B, macroconidia production; and C, conidia germination. the means for AUDPC were numerically higher for the 3-ADON genotype $(277.40 \pm 37.11, F$. austroamericanum $)$ than the NIVproducing strains $(204.9 \pm 19.8)$, with both not differing from the $F$. graminearum $15-\mathrm{ADON}(237 \pm 27.03 \mathrm{SE})$.

Tebuconazole sensitivity. The estimated $\mathrm{EC}_{50}$ values ranged from 0.007 to $1.42 \mu \mathrm{g} / \mathrm{ml}$ across the strains. The highest mean $\mathrm{EC}_{50}$ value was found for one 15 -ADON strain $(1.42 \mu \mathrm{g} / \mathrm{ml})$ whereas, for the others, the values were $<0.5 \mu \mathrm{g} / \mathrm{ml}$. Differences among the genotypes were not apparent across the strains and the limited number of samples prevented formal comparison (Fig. 4).

\section{Discussion}

In this study, we investigated for the first time several traits related to different stages of the saprophytic and pathogenic phases of the FGSC life cycle using a sample of strains representative of four members (and three trichothecene chemotypes) associated with FHB in Brazil. At least for some components evaluated, results are supportive of the hypothesis that $F$. graminearum is more fit than the other species, which may help to explain its dominance as FHB pathogen of wheat in Brazil (Astolfi et al. 2012; Del Ponte et al. 2015; Scoz et al. 2009).

Our most striking result favoring $F$. graminearum was sexual fertility. These homothallic fungi are able to overwinter in crop residues, where they produce perithecia and ascospores, which are able to disperse long distance and infect wheat starting at flowering (Gilbert and Fernando 2004; Khonga and Sutton 1988; Pereyra et al. 2004). Thus, the perithecia production capacity should play an important role in the ecology and epidemiology (Leplat et al. 2013; McMullen et al. 2012). Thus far, few studies have characterized and compared FGSC members or chemotypes within the same species, from the same region or crop, with regards to perithecia and ascospore production (Lee et al. 2012; Liu et al. 2017; Spolti et al. 2014a). Similarly to others (Lee et al. 2009; Liu et al. 2017), we inferred fertility based on the amount of perithecia produced on grain from three main cereal substrates. We found that $F$. graminearum, the only member that possesses the 15-ADON trichothecene genotype in Brazil, produced higher amount of perithecia, followed by the NIV-producing $F$. meridionale and then by the other two species with the 3-ADON or NIV chemotype. Interestingly, this ranking strongly agrees with that of the species frequency found in wheat and barley grain in the region (Astolfi et al. 2011, 2012; Del Ponte et al. 2015).

Previously, the ability of a dominant, kernel-born FGSC member to produce significantly large amounts of perithecia in the original host was observed by Lee et al. (2009), who isolated $87 \%$ of $F$. asiaticum (the main species found in kernels) strains from perithecia developing on rice plants after physiological maturity, followed by $F$. graminearum (13\%). Recently, Liu et al. (2017) compared perithecia production by $F$. asiaticum (NIV and 3-ADON) and $F$. graminearum (15-ADON) from China and found that the latter produced the highest amount of perithecia, which were visible 2 to 3 days earlier than the NIV and 3-ADON strains. In that Chinese region, F. graminearum 15-ADON is also dominant in wheat kernels. In New York, a comparison between $15-\mathrm{ADON}$ and 3-ADON strains of $F$. graminearum from wheat showed no difference in saprophytic and pathogenic fitness toward wheat (Spolti et al. 2014a).

Previously, we found that perithecium-borne $F$. meridionale was highly prevalent in maize stubbles over the surface of two out of three wheat fields, and $F$. graminearum was absent or found at very low frequency in stubbles of all three fields (Del Ponte et al. 2015). We then hypothesized that the former was more fit toward maize, which was further confirmed more recently, because $F$. meridionale was largely dominant on stubbles, stalks, and kernels of maize from Brazil (Kuhnem et al. 2016). In the wheat study, although F. meridionale was dominant in perithecia from maize stubbles on the surface of wheat fields, it was the least frequent in wheat kernels from the same field, which were largely infected by $F$. graminearum (Del Ponte et al. 2015). Our results using three cereal-based substrates suggest that the dominance is not due to enhanced capacity of $F$. meridionale to produce perithecia when compared with $F$. graminearum but to its 
ability to primarily cause stalk rot. Further studies are underway to investigate whether $F$. meridionale is able to outcompete $F$. graminearum in both single and mixed inoculations of maize stalks.

A few other questions remain. For example, it would be instructive to further examine ascospore production and the aerobiology of these species in both controlled and field environments. In our previous field study, F. meridionale was the least frequent $(<30 \%)$ species collected in selective media spore traps during wheat flowering (Del Ponte et al. 2015). Ideally, new studies should include more accurate or less-biased methods, such as molecular identification, given that, during isolations, a fast-growing species may outcompete others. In addition, it would be important to monitor ascosporic inoculum over time and space when both species are present at a similar frequency, similar to another study that used a spore sampler placed near maize stalk residues bearing perithecia with mature ascospores (Manstretta and Rossi 2015). It is well know that FGSC are capable of longdistance dispersal (Prussin et al. 2014) and that airborne populations above wheat canopies may be composed of well-mixed inoculum originated under the effect of turbulence and gravitational settling of inoculum from both local and external sources (Del Ponte et al. 2003; Schmale et al. 2006). The latter hypothesis has been suggested based on both aerobiological and spatial patterns studies in Brazil (Del Ponte et al. 2005; Spolti et al. 2015).

There was a large variation among the isolates from the same species-chemotype with regards to the response to the two suboptimal temperatures tested in our study, thus preventing us from detecting differences in MGR at the species or chemotype level. Previous studies have shown a large sensitivity of $F$. graminearum strains to temperature increase, which was indicative of potential for thermal adaptation (Backhouse 2014; Spolti et al. 2014a; Zhan and McDonald 2011) and saprophytic adaptability (Tunali et al. 2012). In our previous work evaluating MGR of only two $F$. graminearum and two $F$. meridionale strains, growing at four increasing temperatures (10 to $30^{\circ} \mathrm{C}$ ), a significant difference between species was found only at 25 and $30^{\circ} \mathrm{C}$, with $F$. graminearum growing faster than $F$. meridionale (Spolti et al. 2012a). Using a sample as small as eight strains, the maximum difference among strains of $F$. graminearum and $F$. meridionale found in this study was approximately $10 \mathrm{~mm} /$ day, which suggests caution when inferring species differences based on small sample.

Differences in macroconidia production in culture among species may be suggestive of advantages for further spread by asexual means (Leplat et al. 2013). We found that the variation in this trait was very large among isolates of the same species, especially $F$. graminearum and $F$. meridionale, the most represented species, which prevented us from detecting differences as found in our previous studies using a different set of isolates and smaller sample (Spolti and Del Ponte
2013; Spolti et al. 2012a). Recently, Liu et al. (2017) reported significantly greater macroconidia production by $20 \mathrm{~F}$. graminearum $15-$ ADON strains than $20 F$. asiaticum NIV strains but both did not differ from the $F$. asiaticum 3-ADON strains. The germination rate also varied considerably among strains of the same species, which makes largely unclear whether macroconidia production is a reliable variable with which to compare the asexual reproduction fitness among members of the complex, given the inconsistencies and high variability. Moreover, in natural epidemics caused by FGSC, the importance of macroconidia inoculum is not clear, although studies highlighted the potential to dispersal and further infection (Paul et al. 2007).

We found that the species with the DON chemotype were generally more aggressive (higher area under severity curve) than the

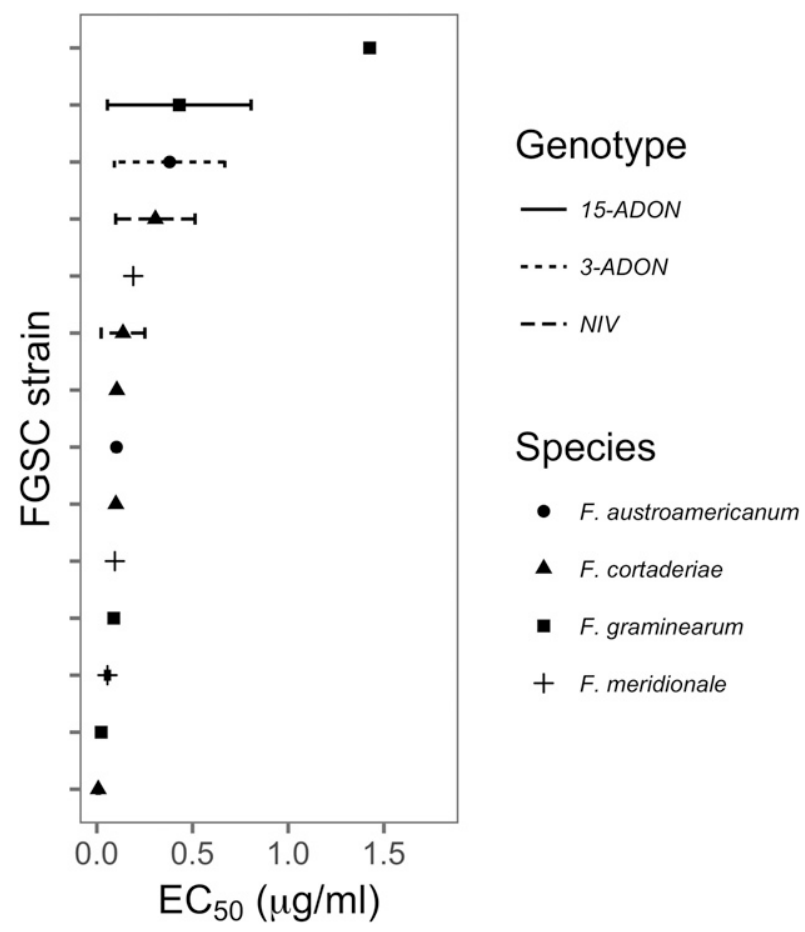

Fig. 4. Effective concentration of tebuconazole that reduces $50 \%\left(E_{50}\right)$ of the mycelial growth of a collection of strains belonging to four Fusarium graminearum species complex members possessing a nivalenol (NIV) or an acetylate form of deoxynivalenol (DON) trichothecene genotype (3-ADON or 15-ADON) found associated with Fusarium head blight of wheat in Brazil.
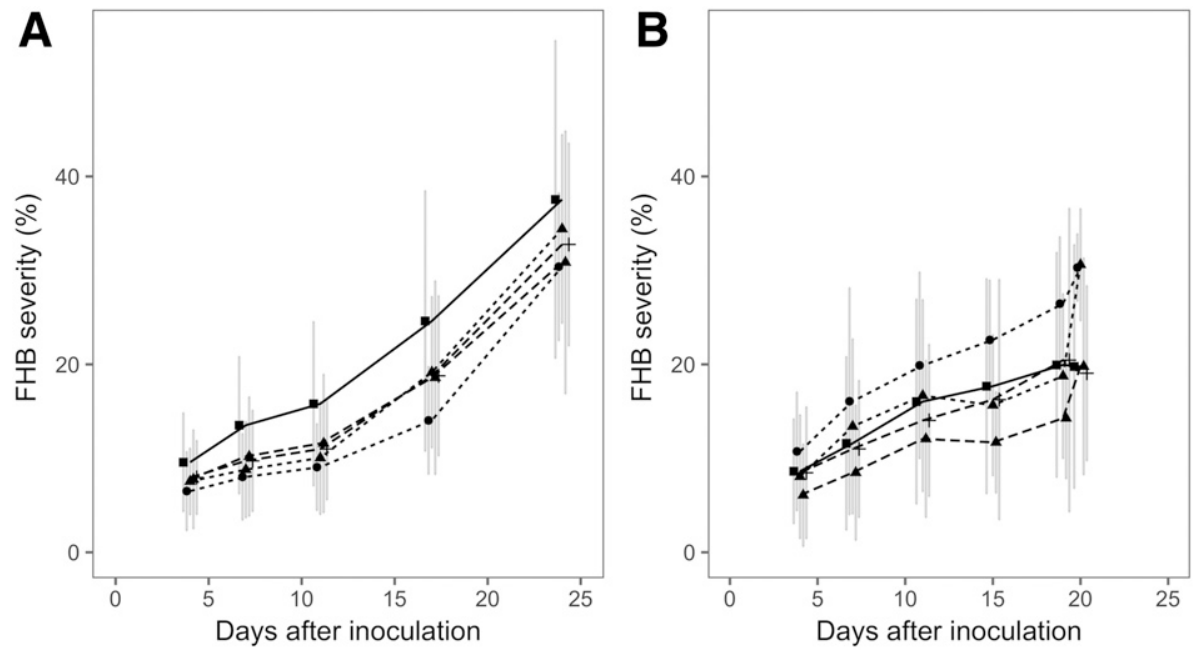

Genotype

$-15-A D O N$

… 3-ADON

$--\cdot N I V$

Species

- F. austroamericanum

- F. cortaderiae

- F. graminearum

+ F. meridionale

Fig. 3. Mean (standard deviation) severity of Fusarium head blight (FHB) in A, moderately resistant cultivar BRS Guamirim and B, susceptible cultivar BRS 194 inoculated with strains of different Fusarium graminearum species complex members possessing a nivalenol (NIV) or an acetylate form of deoxynivalenol (DON) genotype (3-ADON or 15-ADON) found associated with FHB in Brazil. 
NIV species, which is in agreement with our previous studies (Mendes et al. 2018; Spolti et al. 2012a). We could not compare statistically the effect of cultivar because the experiments were conducted at different times and with different total time duration of the evaluations. Nevertheless, the area under the curve was, in general, higher for susceptible BRS 194 compared with BRS Guamirim, as shown earlier (Mendes et al. 2018; Spolti et al. 2012a). For the first time, we compared the two acetylates of DON within the Brazilian strains; although 15-ADON ( $F$. graminearum) was the most aggressive in a susceptible cultivar, the 3-ADON ( $F$. austroamericanum) was the most aggressive in the moderately resistant cultivar, although not significant. Previously, studies comparing strains of these two acetylates of DON showed differences in the rate of colonization, with $15-A D O N$ being more aggressive than NIV, only in the less susceptible BRS Guamirim and not in BRS 194 (Spolti et al. 2012a).

We used the area under the curve of severity and not the final severity (last assessment) (Spolti et al. 2012a) or count of diseased spikelets at individual times (Liu et al. 2017) to compare the strains. Although these measures may be correlated, the area under the curve is more appropriate to capture differences due to variations in the daily progress (e.g., different curve shapes may lead to the same final severity). It would be important to standardize the methodology for assessing FHB pathogen aggressiveness, especially the type of variables and analysis when using central spikelet inoculation in order to compare data from multiple studies. These would include inoculation timing, spore concentration, spikelet position, disease assessment, area under curve of final severity or disease count, and so on. A previous study has shown that, in some cases, the bleaching above the inoculation point for some cultivars was not due to fungal spread but to death of vascular tissue, which is hard to discern visually (Brown et al. 2010; Malbrán et al. 2014). During our observations, we noticed that the total number of spikelets varied among the spikes (data not shown). Therefore, the percent severity may vary slightly when the same number of diseased spikelets is observed in heads of different sizes. The advantages and technical (statistical) issues of using count or proportion data are a topic that deserves further investigation.

We provide data on the tebuconazole sensitivity for five FGSC-chemotype interactions found in southern Brazil but we acknowledge the limitations of our sample sizes. Thus far, few studies evaluated the overall fungicide sensitivity of at least two FGSC members from wheat in Brazil and used either small or more representative sampling ( $>50$ strains) (Spolti et al. 2012a,b). The range of $\mathrm{EC}_{50}$ values found in our study varied not only among but also within isolates of the same species; however, they were within the range reported for $F$. graminearum isolates from the same region (Spolti et al. 2012a). Previously, differences in tebuconazole sensitivity between 3 -ADON and 15-ADON strains within $F$. graminearum from New York State were not found when using large samples ( 25 strains each) (Spolti et al. 2014b). However, our small sample, which is far from being representative of the species $F$. graminearum, was, in general, less sensitive to tebuconazole (because of one less sensitive isolate) than the other, less frequent species. This result agrees specifically with those from a recent study from our group where a larger sample of 15-ADON (48 strains) and the other two genotypes (NIV + 3 -ADON $=17$ strains) from barley was used (Machado et al. 2017). Conversely, in Uruguay, the NIV-producing strains within $F$. asiaticum and $F$. cortaderiae were significantly less sensitive than $15-A D O N F$. graminearum strains. Further molecular studies would help to elucidate the genetic basis of such differences in triazole sensitivity among the FGSC members.

Our results contribute new knowledge to improve our understanding of the ecology and epidemiology of FGSC members, which may be of value for improving models for assessing the risk or epidemics and mycotoxin production. These should include assessing whether there are species-specific environmental requirements for fungal infection, colonization, and mycotoxin production.

\section{Literature Cited}

Allaire, J. J., Xie, Y., McPherson, J., Luraschi, J., Ushey, K., Atkins, A., Wickham, H., Cheng, J., and Chang, W. 2017. rmarkdown: Dynamic Documents for R. R package version 1.8. Online publication. https://cran.r-project.org/web/ packages/rmarkdown/

Astolfi, P., Dos Santos, J., Gomes, L. B., Silva, C. N., Tessmann, D. J., and Del Ponte, E. M. 2011. Molecular survey of trichothecene genotypes of Fusarium graminearum species complex from barley in southern Brazil. Int. J. Food Microbiol. 148:197-201.

Astolfi, P., Reynoso, M. M., Ramirez, M. L., Chulze, S. N., Alves, T. C. A., Tessmann, D. J., and Del Ponte, E. M. 2012. Genetic population structure and trichothecene genotypes of Fusarium graminearum isolated from wheat in southern Brazil. Plant Pathol. 61:289-295.

Backhouse, D. 2014. Global distribution of Fusarium graminearum, F. asiaticum and F. boothii from wheat in relation to climate. Eur. J. Plant Pathol. 139:161-173.

Becher, R., Hettwer, U., Karlovsky, P., Deising, H. B., and Wirsel, S. G. R. 2010. Adaptation of Fusarium graminearum to tebuconazole yielded descendants diverging for levels of fitness, fungicide resistance, virulence, and mycotoxin production. Phytopathology 100:444-453.

Brown, N. A., Urban, M., van de Meene, A. M. L., and Hammond-Kosack, K. E. 2010. The infection biology of Fusarium graminearum: Defining the pathways of spikelet to spikelet colonisation in wheat ears. Fungal Biol. 114:555-571.

Castañares, E., Dinolfo, M. I., Del Ponte, E. M., Pan, D., and Stenglein, S. A. 2016. Species composition and genetic structure of Fusarium graminearum species complex populations affecting the main barley growing regions of South America. Plant Pathol. 65:930-939.

Chen, Y., and Zhou, M. G. 2009. Characterization of Fusarium graminearum isolates resistant to both carbendazim and a new fungicide JS399-19. Phytopathology 99:441-446.

Del Ponte, E. M., Fernandes, J. M. C., and Bergstrom, G. C. 2003. Fusarium head blight and deoxynivalenol accumulation in wheat inoculated at developmental stages from flowering through grain maturation. Pages 129-132 in: Anais, Fusarium Head Blight Forum, St. Paul, MN.

Del Ponte, E. M., Fernandes, J. M. C., and Pavan, W. 2005. A risk infection simulation model for Fusarium head blight of wheat. Fitopatol. Bras. 30:634-642.

Del Ponte, E. M., Spolti, P., Ward, T. J., Gomes, L. B., Nicolli, C. P., Kuhnem, P. R., Silva, C. N., and Tessmann, D. J. 2015. Regional and field-specific factors affect the composition of Fusarium head blight pathogens in subtropical no-till wheat agroecosystem of Brazil. Phytopathology 105:246-254.

Engle, J. S., Madden, V. L., and Lipps, P. E. 2003. Evaluation of inoculation methods to determine resistance reactions of wheat to Fusarium graminearum. Plant Dis. 87:1530-1535.

Gale, L. R., Harrison, S. A., Ward, T. J., O’Donnell, K., Milus, E. A., Gale, S. W., and Kistler, H. C. 2011. Nivalenol-type populations of Fusarium graminearum and $F$. asiaticum are prevalent on wheat in southern Louisiana. Phytopathology 101:124-134.

Gilbert, J., and Fernando, W. D. G. 2004. Epidemiology and biological control of Gibberella zeae/Fusarium graminearum. Can. J. Plant Pathol. 26:464-472.

Juroszek, P., and von Tiedemann, A. 2013. Climate change and potential future risks through wheat diseases: A review. Eur. J. Plant Pathol. 136:21-33.

Khonga, E. B., and Sutton, J. C. 1988. Inoculum production and survival of Gibberella zeae in maize and wheat residues. Can. J. Plant Pathol. 10: 232-239.

Kuhnem, P. R., Del Ponte, E. M., Dong, Y., and Bergstrom, G. C. 2015. Fusarium graminearum isolates from wheat and maize in New York show similar range of aggressiveness and toxigenicity in cross-species pathogenicity tests. Phytopathology 105:441-448.

Kuhnem, P. R., Ward, T. J., Silva, C. N., Spolti, P., Ciliato, M. L., Tessmann, D. J., and Del Ponte, E. M. 2016. Composition and toxigenic potential of the Fusarium graminearum species complex from maize ears, stalks and stubble in Brazil. Plant Pathol. 65:1185-1191.

Lee, J., Chang, I. Y., Kim, H., Yun, S. H., Leslie, J. F., and Lee, Y. W. 2009 Genetic diversity and fitness of Fusarium graminearum populations from rice in Korea. Appl. Environ. Microbiol. 75:3289-3295.

Lee, J., Kim, H., Jin Jeon, J., Kim, J. J., Zeller, K. A., Carter, L. L. A., Leslie, J. F., and Leeb, Y. W. 2012. Population structure of and mycotoxin production by Fusarium graminearum from maize in South Korea. Appl. Environ. Microbiol. 78:2161-2167.

Lenth, R. 2017. emmeans: Estimated Marginal Means, aka Least-Squares Means. $\mathrm{R}$ package version 1.0. Online publication. https://github.com/rvlenth/emmeans

Leplat, J., Friberg, H., Abid, M., and Steinberg, C. 2013. Survival of Fusarium graminearum the causal agent of Fusarium head blight. A review. Agron. Sustain. Dev. 33:97-111.

Leslie, J. F., and Summerell, B. A., eds. 2006. Page 388 in: The Fusarium Laboratory Manual. Blackwell Publishing, Ames, IA.

Liu, Y. Y., Sun, H. Y., Li, W., Xia, Y. L., Deng, Y. Y., Zhang, A. X., and Chen, H. G. 2017. Fitness of three chemotypes of Fusarium graminearum species complex in major winter wheat-producing areas of China. PLoS One 17:0174040.

Machado, F. J., Nicolli, C. P., Möller, P. A., Arruda, R., Ward, T. J., and Del Ponte, E. M. 2017. Differential triazole sensitivity among members of the Fusarium graminearum species complex infecting barley grains in Brazil. Tropic. Plant Pathol. 42:197-202.

Malbrán, L., Mourelos, C. A., Girotti, J. R., Balatti, P. A., and Lori, G. A. 2014 Toxigenic capacity and trichothecene production by Fusarium graminearum isolates from Argentina and their relationship with aggressiveness and fungal expansion in the wheat spike. Phytopathology 104:357-364. 
Manstretta, V., and Rossi, V. 2015. Effects of weather variables on ascospore discharge from Fusarium graminearum perithecia. PLOS ONE 10:e0138860.

McMullen, M., Bergstrom, G., De Wolf, E., Dill-Macky, R., Hershman, D., Shaner, G., and Sanford, D. V. 2012. A unified effort to fight an enemy of wheat and barley: Fusarium head blight. Plant Dis. 96:1712-1728.

Mendes, G. R. L., Del Ponte, E. M., Feltrin, A. C., Badiale-Furlonge, E., and Oliveira, A. C. Common resistance to Fusarium head blight in Brazilian wheat cultivars. Sci. Agric. 75:426-431.

Nicolli, C. P., Spolti, P., Tibola, C. S., Fernandes, J. M. C., and Del Ponte, E. M. 2015. Fusarium head blight and trichothecene production in wheat by Fusarium graminearum and $F$. meridionale applied alone or in mixture at post-flowering. Trop. Plant Pathol. 40:134-140.

O’Donnell, K., Kistler, H. C., Tacke, B. K., and Casper, H. H. 2000. Gene genealogies reveal global phylogeographic structure and reproductive isolation among lineages of Fusarium graminearum, the fungus causing wheat scab. Proc. Natl. Acad. Sci. USA 97:7905-7910.

O’Donnell, K., Ward, T. J., Geiser, D. M., Corby Kistler, H., and Aoki, T. 2004. Genealogical concordance between the mating type locus and seven other nuclear genes supports formal recognition of nine phylogenetically distinct species within the Fusarium graminearum clade. Fungal Genet. Biol. 41: 600-623.

Paul, P. A., Lipps, P. E., Hershman, D. E., McMullen, M. P., Draper, M. A., and Madden, L. V. A. 2007. Quantitative review of tebuconazole effect on Fusarium head blight and deoxynivalenol content in wheat. Phytopathology 97: 211-220.

Pereyra, S. A., Dill-Macky, R., and Sims, A. L. 2004. Survival and inoculum production of Gibberella zeae in wheat residue. Plant Dis. 88:724-730.

Prussin, A. J., II, Li, Q., Malla, R., Ross, S. D., and Schmale, D. G., III. 2014. Monitoring the long-distance transport of Fusarium graminearum from fieldscale sources of inoculum. Plant Dis. 98:504-511.

R Core Team. 2017. R: A Language and Environment for Statistical Computing. Online publication. R Foundation for Statistical Computing, Vienna. https:// www.R-project.org/

Schmale, D. G., III, Leslie, J. F., Zeller, K. A., Saleh, A. A., Shields, E. J., and Bergstrom, G. C. 2006. Genetic structure of atmospheric populations of Gibberella zeae. Phytopathology 96:1021-1026.

Scoz, L. B., Astolfi, P., Reartes, D. S., Schmale, D. G., III, Moraes, M. G., and Del Ponte, E. M. 2009. Trichothecene mycotoxin genotypes of Fusarium graminearum sensu stricto and Fusarium meridionale in wheat from Southern Brazil. Plant Pathol. 58:344-351.

Spolti, P., Barros, N. C., Gomes, L. B., Santos, J., and Del Ponte, E. M. 2012a. Phenotypic and pathogenic traits of two species of the Fusarium graminearum complex possessing either 15-ADON or NIV genotype. Eur. J. Plant Pathol. 133:621-629.

Spolti, P., and Del Ponte, E. M. 2013. Agressividade diferencial de espécies do complexo Fusarium graminearum em interação com o fungicida tebuconazole na redução do rendimento de trigo. Cienc. Rural 43:1569-1575.

Spolti, P., Del Ponte, E. M., Cummings, J. A., Dong, Y., and Bergstrom, G. C. 2014a. Fitness Attributes of Fusarium graminearum isolates from whea in New York possessing a 3-ADON or 15-ADON trichothecene genotype. Phytopathology 104:513-519.

Spolti, P., Del Ponte, E. M., Dong, Y., and Bergstrom, G. 2014b. Triazole sensitivity in a contemporary population of Fusarium graminearum from New York wheat and competitiveness of a tebuconazole-resistant Isolate. Plant Dis. 98:607-613.

Spolti, P., Fernandes, J. M. C., Bergstro, M. G. C., and Del Ponte, E. M. 2015. Disease risk, spatial patterns, and incidence-severity relationships of Fusarium head blight in no-till spring wheat following maize or soybean. Plant Dis. 99:1360-1366.

Spolti, P., Jorge, B. C., and Del Ponte, E. M. 2012b. Sensitivity of Fusarium graminearum causing head blight of wheat in Brazil to tebuconazole and metconazole fungicides. Trop. Plant Pathol. 37:419-423.

Tanaka, T., Hasegawa, A., Yamamoto, S., Lee, U., Ugiura, Y., and Ueno, Y. 1988. Worldwide contamination of cereals by the Fusarium mycotoxins nivalenol, deoxynivalenol and zearalenone. 1. Survey of 19 countries. J. Agric. Food Chem. 36:979-983.

Tunali, B., Obanor, F., Erginbas, G., Westecott, R. A., Nicol, J., and Chakraborty, S. 2012. Fitness of three Fusarium pathogens of wheat. Microb. Ecol. 81:596-609.

Umpiérrez-Failache, M., Garmendia, G., Pereyra, S., Rodríguez-Haralambides, A., Ward, T. J., and Vero, S. 2013. Regional differences in species composition and toxigenic potential among Fusarium head blight isolates from Uruguay indicate a risk of nivalenol contamination in new wheat production areas. Int. J. Food Microbiol. 166:135-140.

Vaughan, M., Backhouse, D., and Del Ponte, E. M. 2016. Climate change impacts on the ecology of Fusarium graminearum species complex and susceptibility of wheat to Fusarium head blight: A review. World Mycotoxin J. 9:685-700.

Ward, T. J., Clear, R. M., Rooney, A. P., O’Donnell, K., Gaba, D., Patrick, S. Starkey, D. E., Gilbert, J., Geiser, D. M., and Nowicki, T. W. 2008. An adaptive evolutionary shift in Fusarium head blight pathogen populations is driving the rapid spread of more toxigenic Fusarium graminearum in North America. Fungal Genet. Biol. 45:473-484.

Zhan, J., and McDonald, B. A. 2011. Thermal adaptation in the fungal pathogen Mycosphaerella graminicola. Mol. Ecol. 20:1689-1701. 